\title{
CARACTERIZAÇÃO MINERALÓGICA E QUÍMICA DAS BAUXITAS DE NAZARÉ PAULISTA (SÃO PAULO)
}

\author{
MARIA L. M. C. SILVA* \& SÔNIA M. B. OLIVEIRA*
}

\begin{abstract}
MINI-RALOGICAL AND CHEMICAL CHARACTERIZATION OF- BAUXITES I ROM NAZARÉ PAL LISTA (SÃO PAI'I.Oi Weathering on metabasic sequence of the Serrado Itaberabaamphibolites led to bauxite formation in top and upper slopes topographic positions. This article deals with mineralogical and geochemical aspects of the fresh rock and its weathering products: bauxite and clay. Microscopic and X-ray diffraction studies indicate that the fresh rock is formed mainly by hornblende, plagioclase and quartz and that gibbsite, kaolinite and goethite are the main phases present in weathered products. The relationship between primary and secondary minerals is discussed. From a geochemical point of view, the bauxitization led to a depletion in Fe, Si, Ca, K, Mg, Mn, P, B, Ba, Be, Cu, La, $\mathrm{Li}, \mathrm{Mo}, \mathrm{Sr}, \mathrm{Sn}, \mathrm{V}, \mathrm{Y}, \mathrm{Zn}$ and $\mathrm{Zr}$ and an enrichment in $\mathrm{Al}, \mathrm{Pb}, \mathrm{Co}$, Cr. REE except Ce, are generally depleted in weathered products. The similarities and differences in the elements behaviour during lateritization was investigated by factor analysis.
\end{abstract}

Keywords: Bauxite, REEduringweathering,geochemistry of weathering.

\begin{abstract}
RESUMO A atuação do intemperismo sobre os anfibolitos da Seqüência Metabásica da Serra do Itaberaba desenvolveu, em regiões de topo e meia encosta, uma cobertura bauxítica objeto deste trabalho. Cinco poços foram abertos em uma toposseqüência localizada na maior destas ocorrências, o Morro da Pedra Preta, e nas proximidades. Além de amostras de rocha fresca com e sem córtex de alteração coletadas em afloramentos, os poços forneceram amostras de dois tipos de alteritas, bauxitas e argilas. Estudos de seções delgadas e difratometriade raios X permitiram identificar a presença de gibbsita, goethita, caul inita e quartzo nas alteritas, e suas relações com os minerais primários (hornblenda, plagioclásio, quartzo, opacos) ao mesmo tempo em que evidenciaram, principalmente nas bauxitas, uma conservação das texturas darocha-mãe, constituindo perfis isalteríticos e permitindo aconclusão de que o processo de bauxitização foi direto. $\mathrm{O}$ tratamento estatístico dos dados de anal ises químicas de elementos maiores e traços e o bal anço geoquímico isovol umétrico efetuado mostraram as diferentes tendências dos elementos durante o processo de laterização. Constata-se que a bauxitização acarretou uma perda em Fe, Si, Ca, K, Mg, Mn, P, B, Ba, Be, Cu, La, Li, Mo, Sr, Sn, $\mathrm{V}, \mathrm{Y}, \mathrm{Zn}$ e $\mathrm{Zr}$ e enriquecimento em $\mathrm{Al}, \mathrm{Pb}, \mathrm{Co}$ e $\mathrm{Cr}$. As terras raras, com exceção do Ce, são, em geral, lixiviadas nos produtos de alteração.
\end{abstract}

Palavras-chaves: Bauxita, ETRno intemperismo, geoquímica do intemperismo.

INTRODUÇÃO A região da Serra do Itaberaba, localizada nos limites dos municípios de Nazaré Paulista, Guarulhos e Santa Isabel, cerca de $45 \mathrm{~km}$ a nordeste da cidade de São Paulo (Fig. 1), tem sido estudada apenas recentemente. Em 1981, o projeto "Avaliação preliminar das potencialidades das ocorrências minerais do Estado de São Paulo" (IPT PROMINÉRIO 1982) levou à caracterização de uma série de ocorrências de bauxita, desenvolvidas por laterizacão de anfibolitos, ao mesmo tempo que despertou o interesse pela prospecção de ouro e metais base, objeto de diversos projetos posteriores.

Dos corpos de bauxita definidos nesta primeira fase, 16 foram detalhados e avaliados, culminando nos dados de reserva apresentados por Beljaviskis et al. (1984). Foi estimada uma reserva total de 5.600 .0001 , com os seguintes teores médios do minério in natura: 34,85 de AUOs (total), 7,7\% de $\mathrm{SiO}_{2}$ (reativa) e $28,8 \%$ de $\mathrm{Fe}_{2} \mathrm{O}_{3}$. As áreas de bauxita, desde sua avaliação, não integraram mais os projetos do IPT.

Além da caracterização química e mineralógica de bauxita e dos demais materiais de alteração, este trabalho visa contribuir para um melhor conhecimento da gênese desse depósito.

A ÁREA ESTUdAdA A área estudada situa-se no Morro da Pedra Preta que corresponde à maior das ocorrências de bauxita da Serra do Itaberaba (Fig. 2) avaliadas por Beljaviskis et al. (1984).

A Serra do Itaberaba está inserida na Serrania de São Roque, subdivisão do Planalto Atlântico. Trata-se de região de clima mesotérmico úmido, sem estação seca, com verão fresco. A temperatura média anual varia entre máxima e mínima médias de $26^{\circ} \mathrm{C}$ e $16^{\circ} \mathrm{C}$ e a precipitação média anual entre 1.300 e $1.700 \mathrm{~mm}$. A vegetação original do tipo latifoliada tropical ocorre em áreas restritas e vem sendo substituída por reflorestamento de pinus e eucaliptos (Mapa Geomorfológico do Estado de São Paulo, IPT 1981).

Em decorrência dos trabalhos de prospecção que vêm sendo executados pelo IPT, Coutinho et al. (1982) definiram na região uma seqüência vulcano-sedimentar, considerada por esses autores como membro basal do Grupo São Roque. Mais tarde, Juliani et al (1986) propuseram a individualização desta seqüência sob a denominação Grupo Serra do Itaberaba. Diversos tipos litológicos foram descritos pelos vários autores que estudaram a área e podem ser agrupados em três subseqüências de rochas. Ocupando cerca de $40 \%$ da área de ocorrência do Grupo Serra do Itaberaba, estão os anfibolitos da subseqüência metabásica, rocha-mãe dos depósitos de bauxita. São rochas de granulação variando de fina a média e cuja composição mineralógica é caracterizada por hornblenda, com quantidades subordinadas de plagioclásio e com quartzo, titanita, epídoto e opacos como acessórios.

Os demais tipos litológicos presentes estão inseridos nas subseqüências cálcio-silicática (paranfibolitos resultantes de metamorfismo de grau médio sobre margas e dolomitos) e metapelítica (filitos e xistos finos). Intercalados nas diversas litologias, são identificadas camadas de quartzitos mais ou menos ferruginosos. Ocorrem, ainda, cortando a seqüência vulcanossedimentar, rochas graníticas que constituem o batólito de Pedra Branca de Hasui et al. (1978), da fácies 


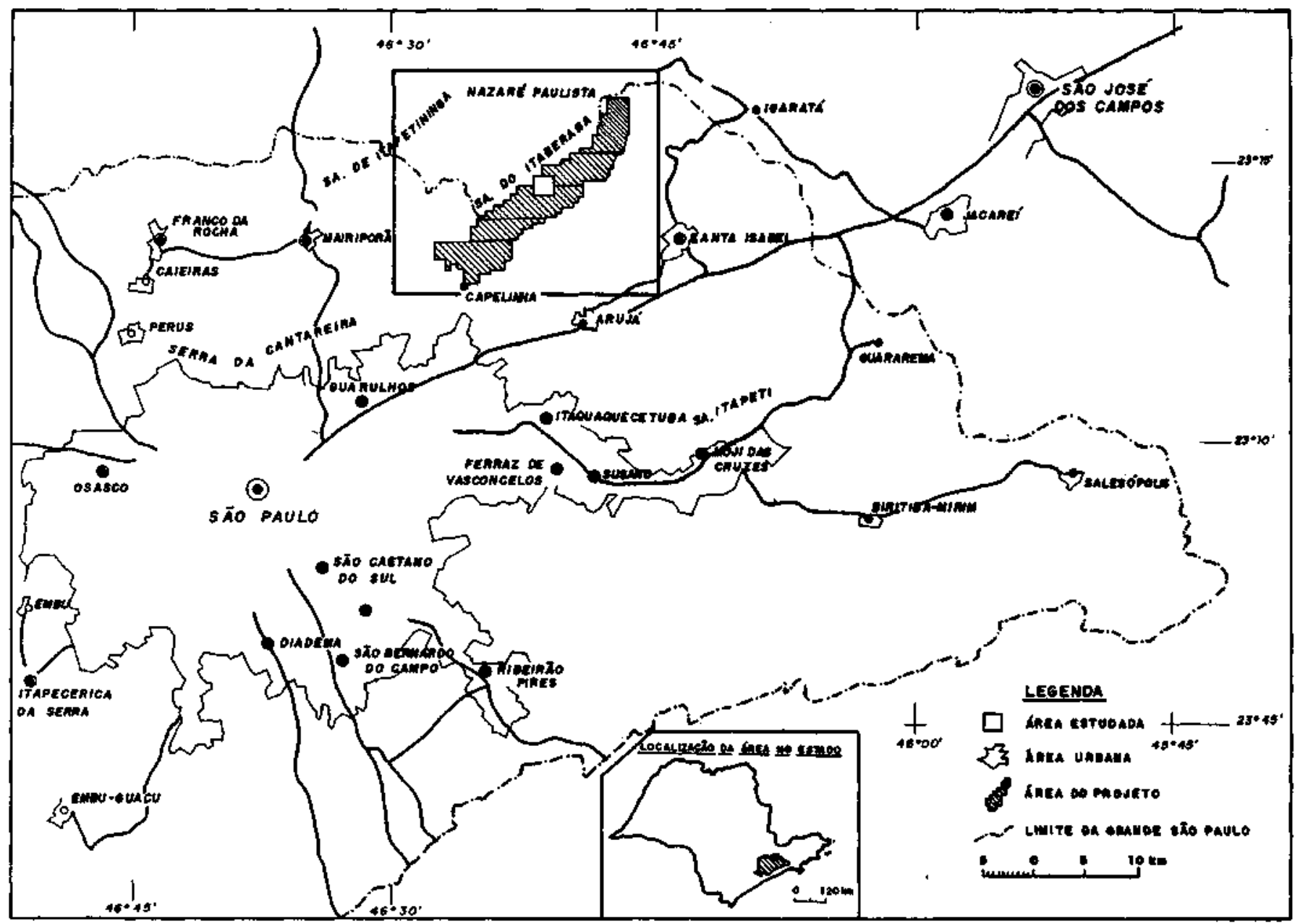

figura 1 - Localização cia área estudada

Figure 1 -Localization of the studied area

litológica Cantareira (Coutinho et al. 1982, Juliani et al 1986, Frasca et al 1987).

O Morro da Pedra Preta é constituído, essencialmente, por anfibolitos da seqüência metabásica com finas lentes intercaladas de quartzo-muscovita xisto da seqüência metassedimentar (Fig. 2).

AMOSTRAGEM E MÉTODOS Cinco poços com seção retangular de $1,00 \mathrm{~m} \times 0,80 \mathrm{~m}$ foram abertos. Os poços A, B, C e D constituem uma toposseqüência localizada no principal corpo de bauxita definido pelo I PT em 1982 (Fig. 2). $\mathrm{O}$ quinto poço foi aberto no centro de uma anomalia geoquímica de cromo, detectada durante os trabalhos de prospecção, a qual corresponde a uma pequena elevação contígua àquele corpo de bauxita.

Os poços não atingiram a rocha fresca e, conseqüentemente, não foi possível fazer uma amostragem da transição rocha fresca/rocha alterada, o que dificultou uma definição mais precisa das filiações mineralógicas e da própria gênese do material. Amostras de rocha fresca e blocos desta com córtex de alteração bauxítico foram coletadas em afloramentos próximos aos poços abertos.

Foram obtidas 37 amostras nos poços e três amostras em afloramentos. Algumas destas, por constituírem materiais heterogêneos, foram desdobradas, de modo que o total de amostras utilizadas neste trabalho chegou a 50. Os estudos petrográficos basearam-se em lâminas delgadas e difratogramas de raios $\mathrm{X}$, confeccionadas após endurecimen- to por impregnação com resina. Os seguintes elementos foram analisados, por ICP, nas 50 amostras: Al, B, Ba, Be, Ca, $\mathrm{Ce}, \mathrm{Co}, \mathrm{Cr}, \mathrm{Cu}, \mathrm{Fe}, \mathrm{K}, \mathrm{La}, \mathrm{Li}, \mathrm{Mg}, \mathrm{Mn}, \mathrm{Mo}, \mathrm{P}, \mathrm{Pb}, \mathrm{Si}, \mathrm{Sn}, \mathrm{Sr}$, Ti, Y, V, Zn, Zr. O teor de $\mathrm{H}_{2} \mathrm{O}^{+}$foi calculado por diferença. Análises de terras raras foram executadas nas 28 amostras dos poços A, B e C, também por ICP.

OS MATERIAIS ESTUDADOS Foram amostrados e estudados dois tipos de materiais: rocha fresca e alteritas. A rocha fresca é constituída pelos anfibolitos já citados, que são rochas mineralogicamente homogêneas, de composição simples e granulação variando de fina a grossa. As texturas observadas, granonematoblástica, blastofítica, blastoporfirítica e decussada, indicam uma origem ígnea, a partir de basaltos, tratando-se, portanto, de ortoanfibolitos. Cerca de $85 \%$ em volume da rocha é constituído por hornblenda poiquilítica com inclusões principalmente de quartzo, o que indica uma provável formação a partir de clinopiroxênio. Os plagioclásios constituem cerca de $10 \%$ em volume e, raramente, no caso das seções estudadas, mostram geminação característica. Apresentam-se em cristais geralmente menores do que a hornblenda, salvo em rocha de granulação muito fina, onde esta relação se inverte. Como acessórios, ocorrem, ainda, quartzo, clinozoisita, titanita e opacos (possivelmente ilmenita). Algum sulfeto foi verificado em uma das amostras. As alteritas compreendem às bauxitas e aos materiais argilosos. A bauxita, macroscopicamente, é de coloração amarelo-avermelhada, com porosidade fina predominante, 


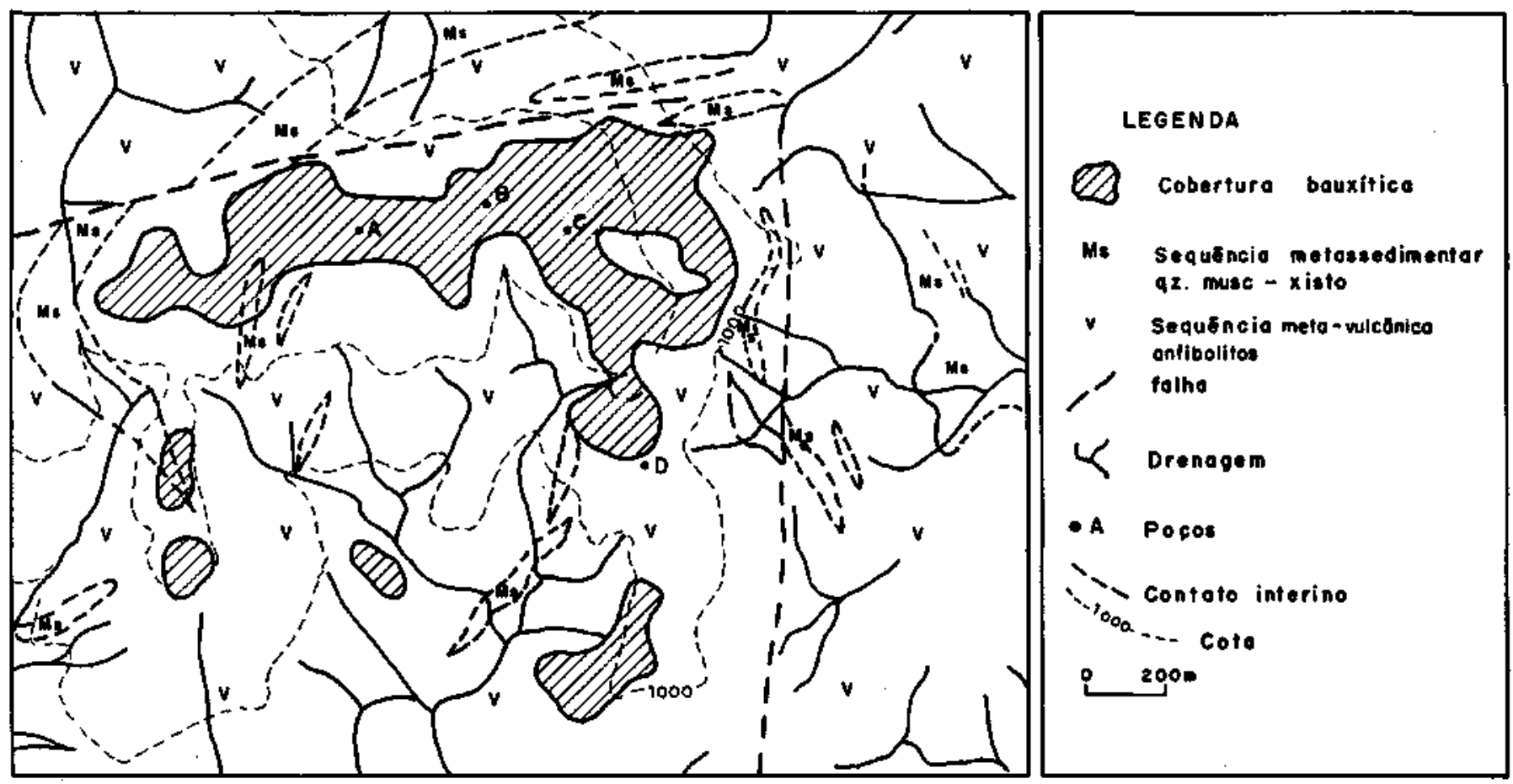

Figura 2 - Mapa geológico do morro da Pedra Preta com delimitação da cobertura bauxítica e localização dos poços A, B, CeD

Figure 2 - Geologic map of the Pedra Pretahill indicating limits of the bauxitic cover and localization of A, B, C and D wells

apresentando-se de maneira compacta ou em blocos imersos em matriz argilosa. Esta matriz e os demais materiais argilosos são de coloração variada, em especial amarelo-avermelhada. A bauxita é constituída essencialmente por gibbsita, com quantidades menores de goethita e quartzo, além de traços de caulinita e opacos. Ao microscópio, a goethita apresenta-se, quase sempre, em pseudomorfose sobre a hornblenda, constituindo uma rede imersa em cristaliplasma gibbsítico com vazios por vezes preenchidos por gibbsita. Imersos neste cristaliplasma estão os cristais de quartzo apresentando, em geral, feições de dissolução e, mais raramente, opacos que podem também apresentar, eventualmente, alguma feição de dissolução. Não foi possível a identificação da caulinita em seções delgadas de bauxita, razão pela qual não se pode precisar sua relação com os demais minerais presentes. A quase completa ausência de cutans e outras feições pedológicas, aliadas à presença de pseudomorfoses e à conservação da estrutura da rocha-mãe, levam a classificar a bauxita como isalterítica.

A argila possui uma predominância de caulinita em relação aos demais minerais, identificados como goethita, quartzo e, mais raramente, gibbsita. As seções delgadas revelam a presença de goethita pseudomorfísando hornblenda. Por vezes este mineral ocupa cerca de 80 a $90 \%$ da seção delgada, dificultando a identificação dos demais minerais presentes. A caulinita constitui um cristaliplasma e, em algumas poucas amostras, aparecem cristais muito bem formados, constituindo as "sanfonas". Os níveis argilosos dos poços A, B e C, que apresentam conservação das texturas originais da rocha-mãe, podem ser classificados como isalteríticos. Nas seções delgadas das argilas dos poços D e E, a conservação das texturas da rocha-mãe é mais rara; existem mais registros de feições pedológicas como veios preenchidos por goethita ou por óxidos de manganês e caulinita bem cristalizada, mas, de modo geral, não ficou bem definida a presença de cutans. Há, no entanto, algum indício de separação plásmica em função da alternância de umectação e dissecação.
A passagem rocha fresca/rocha alterada, por não ter sido atingida pelos poços, é de difícil definição. No entanto, de acordo com o relatório I PT (1982), nos topos, a bauxita assenta diretamente sobre o anfibolito fresco enquanto os níveis argilosos vão aparecendo nas partes mais baixas das encostas. Este nível, caulinítico, na base de alguns perfis, citado por Beljaviskis et al. (1984), não foi observado nos poços estudados. Estes autores citam a presença, na base dos perfis, de núcleos de anfibolito fresco com córtex bauxítico.

A distribuição dos diferentes materiais parece controlada pela topografia, ou seja, acima de $1.000 \mathrm{~m}$, a tendência da alteração é para formação de bauxita com maiores espessuras e presença de bauxita compacta. Entre $1.000 \mathrm{~m}$ e $930 \mathrm{~m}$, forma-se bauxita com espessura menor e teores de silica reativa mais altos (acima de 10\%), indicando quantidades maiores de caulinita, ao lado de bauxita em blocos. Em cotas inferiores, aparecem raros blocos de bauxita em horizontes coluvionares com até cerca de $1 \mathrm{~m}$ de espessura, passando a perfis totalmente argilosos.

É interessante ressaltar a presença de filmes de oxido de manganês, geralmente acompanhado por caulinita, que parecem ter se formado em fraturas da rocha fresca (Beljaviskis et al. 1984). Estes filmes estão presentes desde o topo do perfil, parecendo estar em maior quantidade nos materiais mais argilosos e em maiores profundidades. Este tipo de ocorrência de oxido de manganês foi constatado em outros depósitos de bauxita como Curucutu e Lavrinhas (SP) (ToledoGroke \& Melfi 1982); Cataguases (MG) (Lopes 1987), Lages (SC) (Oliveira 1985) e Orumbo-Boca (Costa do Marfim) (Boulangé 1984).

AS FILIAÇÕES MINERALÓGICAS Por meio do estudo micromorfológico, foi possível identificar a seqüência de alteração dos principais minerais presentes na rocha sã.

Hornblenda Sua alteração inicia-se pela hidrólise do mineral primário ao longo das fraturas, seguida pela 

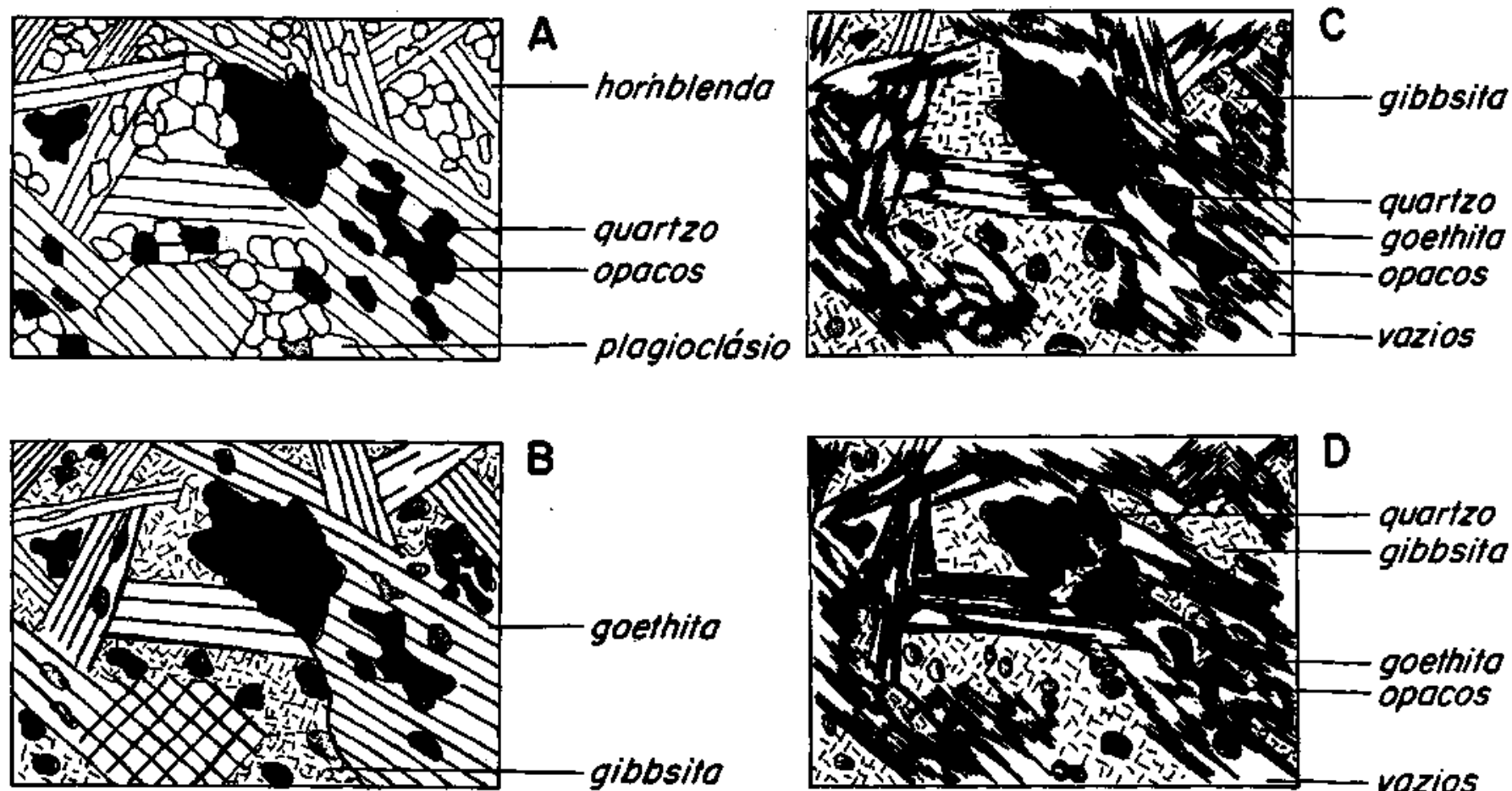

Figura 3 - Esquema de alteração anfibolito/bauxita, mostrando a conservação das texturas da rocha-mãe. A. Rocha fresca; B. Início da alteração: deposição de goethita nas descontinuidades da hornblenda e gibbsitização dos feldspatos; C. Alteração mais intensa: aparecimento de vazios no interior das pseudomorfoses de hornblenda e feições de dissolução do quartzo; D. Bauxita: rede de goethita com paredes espessas, em cristaliplasma gibbsitico Figure 3 - Amphibolite-bauxite weathering schema, showing the conservation ofthe texture of the original rock. A. Fresh rock; B. Beginning of Weathering: goethite deposition in hornblend discontinuities and feldspar gibbsitization; $C$. More intense weathering: void appearence in the interior of hornblend pseudomorphs and dissolution features in quartz; D. Bauxite; goethite thick walls in gibbsiticcrystalliplasm

individualização do ferro na forma de goethita depositada nas paredes e fissuras internas dos cristais. Prossegue com a dissolução dos núcleos ainda frescos e formação de vazios responsáveis por um aumento da porosidade das alteritas. Estes vazios podem ser preenchidos por gibbsita em estágios mais avançados de alteração, embora raramente sejam encontrados pseudomorfos de hornblenda com núcleos ainda frescos ao lado de vazios preenchidos por gibbsita. $\mathrm{O}$ produto desta alteração é, finalmente, uma rede de goethita relativamente espessa, com eventual preenchimento dos vazios por gibbsita.

O padrão de alteração de ferromagnesianos como piroxênios e anfibólios, resultando numa rede goethítica com vazios, foi descrito por diversos autores em bauxitas desenvolvidas sobre rocha básica (Delvigne 1965, Toledo-Groke \& Melfi 1982, Boulangé 1984 e Lopes 1987). O eventual preenchimento por gibbsita foi referido também por Boulangé (1984). No entanto, uma explicação para a precipitação deste mineral in situ $e ́$ complexa, posto que o alto $\mathrm{pH}$ de abrasão dos minerais ferromagnesianos criaria condições para que o $\mathrm{Al}$ se encontrasse na forma solúvel de ânion alum inato, com tendência a migrar, como sustenta Delvigne (1965). Boulangé (1984) propõe que o crescimento dos cristais de gibbsita ocorreria nos vazios, a partir da formação de um germe in situ por aporte de $\mathrm{Al}$ proveniente das cavidades ou outros minerais vizinhos. A formação deste germe permanece sem explicação.

Plagioclásios A alteração destes minerais para gibbsita é bastante brusca. Logo no início do processo, esses minerais desaparecem sendo substituídos por um cristaliplasma gibbsítico envolvendo cristais ainda frescos a muito ligeiramente alterados de hornblenda, titanita, opacos etc. Devido provavelmente ao pequeno tamanho dos cristais de plagioclásio na rocha-mãe, não são reconhecíveis pseudomorfoses deste mineral e, muito raramente, foram constatados vazios neste cristaliplasma. Isto pode significar que o alumínio presente nas hornblendas contribui para a formação de gibbsita, como aventado por Delvigne (1965), ocupando espaços que seriam gerados pela lixiviação dos elementos solúveis presentes nos plagioclásios. De fato, o balanço geoquímico mostra que não há perda de alumínio durante o processo de alteração.

Quartzo Os grãos de quartzo, juntamente com os opacos, são os principais componentes do esqueleto em amostras mais alteradas. Apresentam-se geralmente em grãos pequenos, fraturados, com contornos irregulares formados por dissolução. As feições de dissolução são comuns desde o início da alteração, estando os espaços gerados ocupados por gibbsita ou, eventualmente, goethita em amostras mais argilosas. Em algumas lâminas, a fragmentação do quartzo devida aos processos de dissolução é tão intensa que este fica disperso no cristaliplasma gibbsítico, com os diferentes fragmentos apresentando extinção simultânea, atestando assim, conservação da estrutura da rocha.

Titanita Este mineral aparentemente se altera ao mesmo tempo que a hornblenda. Porém, não foi identificado por difração de raios X nenhum mineral de titânio nas alteritas. A titanita normalmente se altera para anatásio, em condições de laterização.

Clinozoisita É mais resistente que hornblenda, plagioclásio e titanita, tendo sido reconhecida em todo o córtex de alteração, quando aqueles minerais já haviam se transformado. No entanto, devido à falta de amostras da transição rocha fresca/rocha alterada, não foi possível verificar em que nível e como se altera. Devido à sua composição química, é possível que este mineral siga caminho semelhante ao do plagioclásio, 

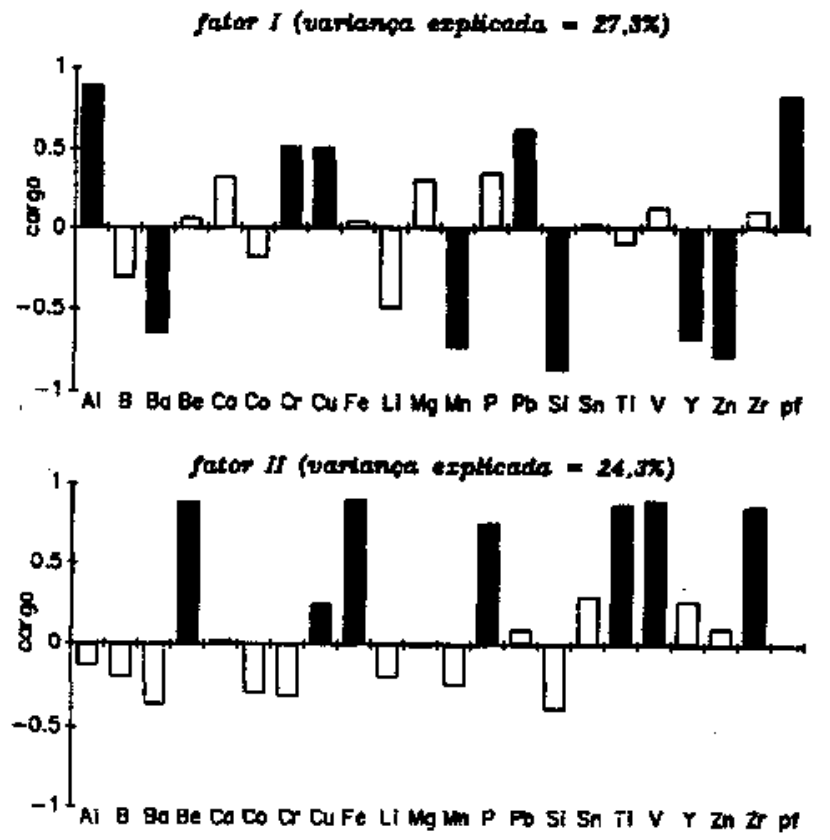

Figura 4 - Composição dos fatores obtidos na análise fator ial varimax. Barras cheias destacam os elementos com carga maior que 0,5

Figure 4 - Composition of factors obtained in the varimax factorial analysis

alterando-se para caulinita ou gibbsita, de acordo com a intensidade e o tipo do processo de intemperismo atuante. Contudo a única referência encontrada, Bullock et al. (1985), cita que a alteração de epídoto se dá por dissolução, à semelhança do quartzo, fato este não comprovado nas seções delgadasestudadas.

Opacos Os opacos persistem em todos os níveis de alteração, sendo, no entanto, bastante raros em algumas lâminas e razoavelmente abundantes nas frações pesadas. Trata-se, provavelmente, de magnetita e ilmenita que apresenta alteração endógena para titanita. Feições de dissolução são observadas, apresentando-se como descontinuidades preenchidas por gibbsita ou por goethita. Ao microscópio, nas frações pesadas, aparece uma película de oxidação, provavelmente de goethita, envolvendo cristais de magnetita.

A presença de caulinita no perfil de alteração foi determinada tanto por difração de raios X, quanto em seções delgadas. Aparece em seções delgadas de material argiloso, finamente cristalina ou, raramente, formando sanfonas. Nas seções delgadas de bauxita não foi vista, embora sua presença em pequena quantidade tenha sido atestada pela difração de raios X. A falta de amostras dos níveis inferiores do perfil de alteração não permitiu estabelecer sua origem.

A figura 3 esquematiza a seqüência de alteração anfibolito/ bauxita com conservação das texturas da rocha-mãe, ilustrando as filiações descritas .

EVOLUÇÃO GEOQUÍMICA A composição química média dos três tipos de materiais presentes é apresentada na tabelai. A análise desses dados leva ao reconhecimento de três grupos de elementos: os que se apresentam nitidamente enriquecidos em relação à rocha fresca $(\mathrm{Al}, \mathrm{Fe}, \mathrm{Cr}, \mathrm{Cu}, \mathrm{Pb}, \mathrm{V}$, $\mathrm{Zr}$ ) e, neste caso, mais enriquecidos nas bauxitas do que nas argilas; os que estão nitidamente empobrecidos em relação a rocha fresca ( $\mathrm{Si}, \mathrm{Ca}, \mathrm{Mg}$ e $\mathrm{Sr}$ ); os que não apresentam tendência bem marcada, variando apenas ligeiramente nos diferentes materiais (B, Ba, Be, Co, Li, Mo, Sn, V, Y, Zr, Ti, $\mathrm{K}, \mathrm{Mn}, \mathrm{P})$. Esses últimos elementos apresentam geralmente
Tabela 1 - Composição química média dos três tipos de materiais Table 1 -Chemical composition of the three types of materials

\begin{tabular}{|c|c|c|c|}
\hline & RochaFresca & Bauxita & Argila \\
\hline & $n=3$ & $n=17$ & $n=30$ \\
\hline \multicolumn{4}{|c|}{$\%$ empeso de elementos matores } \\
\hline $\mathrm{SiO}_{z}$ & 48,80 & 8,10 & 27,00 \\
\hline $\mathrm{THO}_{2}$ & 1,40 & 1.90 & 1,7 \\
\hline $\mathrm{Al}_{2} \mathrm{O}$ & 14,00 & 37,40 & 27,10 \\
\hline $\mathrm{Fe}_{2} \mathrm{O}_{4}$ & 16,40 & 29,30 & 25,60 \\
\hline $\mathrm{CaO}$ & 9,52 & 0,03 & 0,03 \\
\hline $\mathrm{K}_{2} \mathrm{O}$ & 0,06 & 0,06 & 0,07 \\
\hline $\mathrm{MgO}$ & 11,77 & 0,09 & 0,08 \\
\hline $\mathrm{MiO}_{2}$ & 0,24 & 0,09 & 0,24 \\
\hline $\mathrm{P}_{2} \mathrm{O}_{4}$ & 0,14 & 0,20 & 0,12 \\
\hline \multirow[t]{2}{*}{$\underline{\mathrm{H}_{1} \mathrm{O}}$} & - & 22,80 & 18,00 \\
\hline & \multicolumn{2}{|c|}{ Flementos Tracos em ppm } & \\
\hline B & 5 & 7 & 17 \\
\hline $\mathrm{Ba}$ & 30 & 19 & 54 \\
\hline $\mathrm{Be}$ & 2 & 3 & 3 \\
\hline Co & 60 & 72 & 88 \\
\hline $\mathrm{Cr}$ & 74 & 558 & 255 \\
\hline $\mathrm{Cu}$ & 164 & 295 & 182 \\
\hline $\mathbf{L i}$ & 22 & 8 & 14 \\
\hline Mo & 5 & 5 & 5 \\
\hline $\mathrm{Pb}$ & 56 & 117 & 88 \\
\hline Sa & 56 & 67 & 63 \\
\hline Sr & 95 & 3 & 3 \\
\hline$v$ & 419 & 673 & 532 \\
\hline $\mathbf{Y}$ & 28 & 4 & 10 \\
\hline Zn & 121 & 58 & 101 \\
\hline $\mathbf{Z r}$ & 70 & 126 & 96 \\
\hline
\end{tabular}

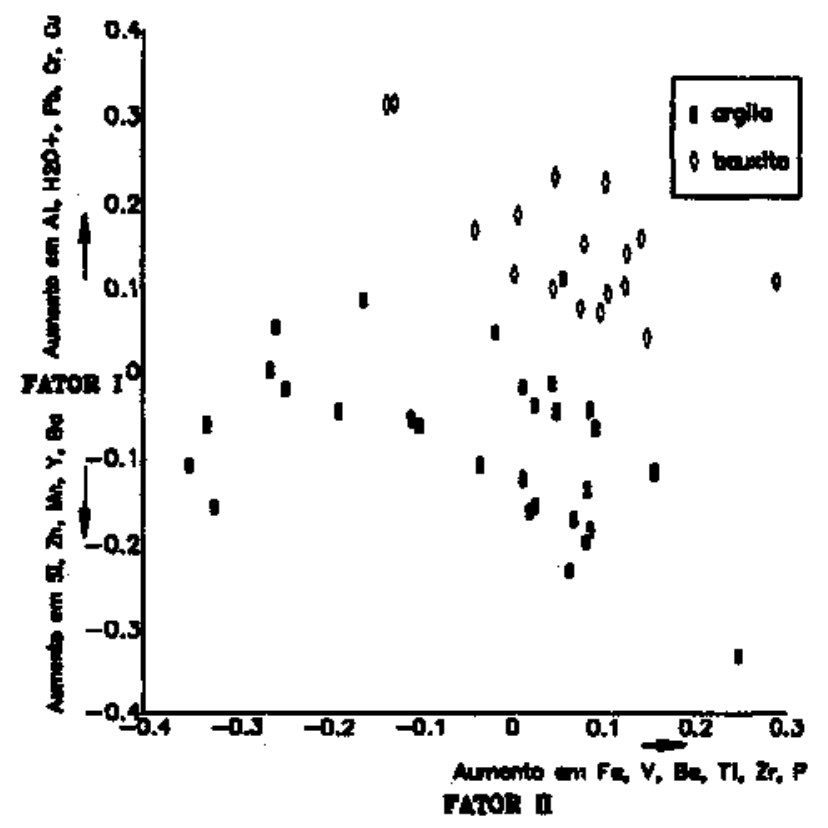

Figura 5 - Diagrama dos scores dos fatores, distinguindo entre amostras de bauxiía e argila

Figure 5 - Factors' scores diagram, identifying clay and bauxite samples

maiores valores nas argilas, em relação às bauxitas.

O tratamento estatístico efetuado com os dados das análises químicas, correlação Pearson e análise de componentes principais apresentado por Silva \& Oliveira (1989) puseram em evidência o relacionamento entre as espécies químicas, identificando três grupos: grupo do $\mathrm{Al}\left(\mathrm{Cr}, \mathrm{Cu}, \mathrm{Pb}, \mathrm{H}_{2} \mathrm{O}+\right)$, grupo do $\mathrm{Si}(\mathrm{Mn}, \mathrm{Zn}, \mathrm{Ba})$ e grupo do $\mathrm{Fe}(\mathrm{Be}, \mathrm{P}, \mathrm{Ti}, \mathrm{V}, \mathrm{Zr})$. 


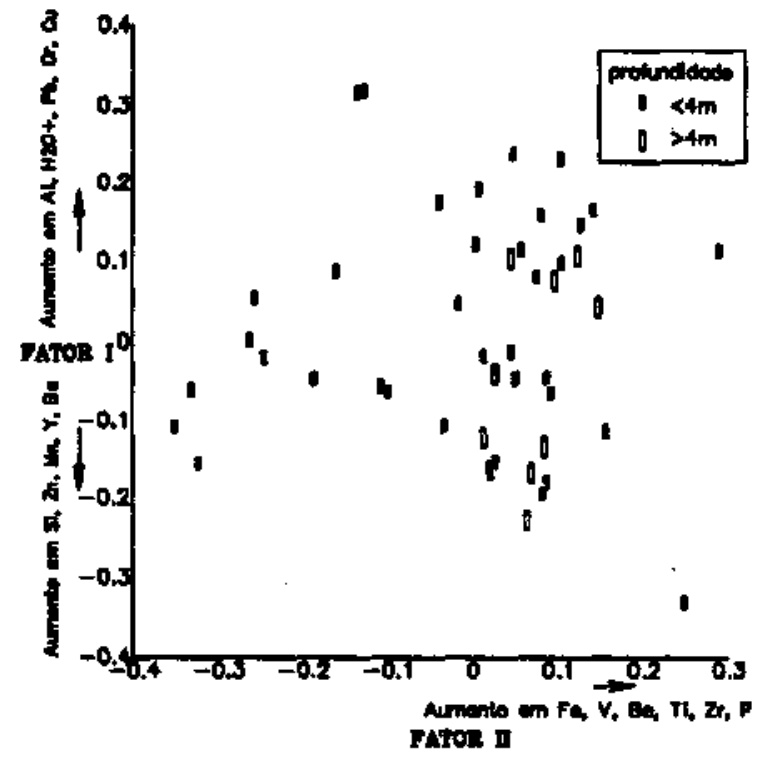

Figura 6 - Diagrama dos scores dos fatores, distinguindo entre amostras de profundidades maior e menor que $4 \mathrm{~m}$ Figure 6 - Factors' scores diagram, separating samples from depths greater than and smaller than $4 \mathrm{~m}$

A análise fatorial modo $\mathrm{R}$, pelo sistema Varimax, utilizando o modelo de dois fatores (responsáveis por $51,5 \%$ da variança total explicada) mostra resultados semelhantes aos anteriores. A composição dos fatores apresentada na figura 4 mostra que o fator I é composto principalmente (carga $>0,5$ ) pelos elementos do grupo do $\mathrm{Al}\left(+\mathrm{H}_{2} \mathrm{O}^{+}\right)$com carga positiva e pelos do grupo do Si com carga negativa, sendo assim capaz de distinguir entre amostras de bauxita e argila, como pode ser verificado na figura 5. O fator II, que é composto principalmente pelos elementos do grupo do $\mathrm{Fe}($ carga $>0,5)$, foi utilizado para auxiliar na compreensão do comportamento deste grupo de elementos. Na figura 6 , o diagrama Fator I x Fator II distingue as amostras provenientes de profundidades maiores e menores do que $4 \mathrm{~m}$, mostrando que as mais profundas têm sempre teores mais altos nos elementos do grupo do $\mathrm{Fe}$, sugerindo migração per descensum destes elementos. De fato, cristais de goethita bem formados, originados provavelmente de precipitação após transporte do Fe em solução, são mais freqüentes em amostras de níveis inferiores dos poços estudados.

Em função da preservação das estruturas nos materiais alterados, foi possível realizar cálculos de balanço isovolumétrico com a finalidade de determinar as perdas e ganhos durante a alteração. Na figura 7, são apresentadas as faixas de variação das porcentagens de perdas e ganhos com relação à rocha fresca, para os elementos estudados. Verificase que a maioria dos elementos é lixiviada durante a alteração, sendo Fe e Ti (entre os maiores) e Be, Li, P, Sn, V e Zr menos intensamente que Si e Ca (entre os maiores) e $\mathrm{Ba}, \mathrm{Sr}, \mathrm{Y}$ e Zn. Os únicos elementos que apresentam enriquecimento absoluto são $\mathrm{Ce}$, $\mathrm{Co}$ e $\mathrm{Cr}$. Al e $\mathrm{Pb}$ são mais ou menos conservados no perfil e, portanto, apresentam um enriquecimento apenas relativo. Evidencia-se, desta forma, a atuação de um processo de intemperismo tipicamente laterizante, com lixiviação das bases e da silica (esta menos intensa no nível argiloso do perfil estudado), conservação total do $\mathrm{Al}$ e parcial do $\mathrm{Fe}$, gerando assim as bauxitas ferruginosas.

O comportamento das terras raras durante o intemperismo dos anfibolitos caracteriza-se por perda generalizada destes elementos, com exceção do $\mathrm{Ce}$. O enriquecimento em $\mathrm{Ce}$ deuse principalmente no poço $\mathrm{B}$, acompanhando o comporta-

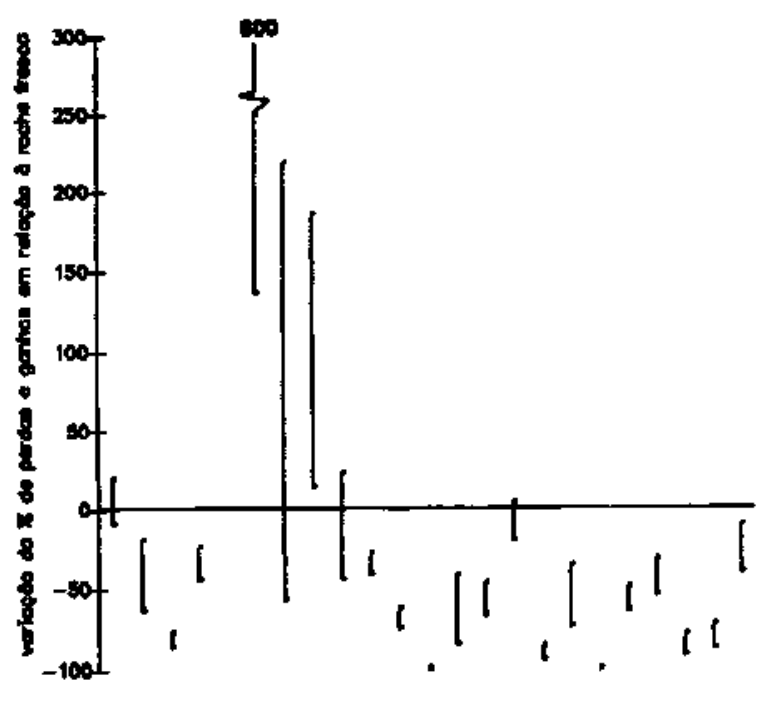

Al B BoB«CoC «CoCrCuF» Ü MgMn P Pb Si Sn Sr TI V Y Zn Zr

Figura 7 - Variação das porcentagens de per das e ganhos de matéria em relação à rochafresca, determinadas por balanço isovolumétrico

Figure 7 - Percentage variation of losing, and gain in relation to fresh rock, determinated by isovolumetric balance

mento do $\mathrm{Co}$, elemento com o qual, além do $\mathrm{Cu}, \mathrm{Y}, \mathrm{Mn}$ e das demais terras raras, encontra-se correlacionado. Nos diagramas de normalização dos dados, nota-se que a perda das TR pesadas é ligeiramente menos acentuada que das TR leves (Silva \& Oliveira 1989; Oliveira \& Silva 1990).

Podemos dizer que as TR comportam-se de maneira semelhante aos demais elementos de comportamento solúvel, tendo sido bastante lixiviadas dos perfis de alteração. Em virtude da alta correlação positiva do Ce e demais TR com Co eMn, sugere-se que o comportamento destes elementos esteja interligado. Possivelmente, as concreções de Mn (provavelmente litioforita) presentes nestes perfis se comportaram como uma armadilha para o aprisionamento das TR, principalmente o Ce, a exemplo do que ocorre comumente com o Co. Esta associação das TRcom oxi-hidróxidosde Mn foi verificada por Formoso et al. (1989) nas bauxitas de Lages (SC) e referida por Roquin et al (1990) nas alteritas do sudeste do Mali.

CONSIDERAÇÕES FINAIS É nos topos e meias encostas que os anfibolitos, devido a um intenso processo de laterização, desenvolveram um perfil bauxítico. À medida que se caminha para regiões topograficamente mais baixas, os perfis vão se tornando mais argilosos. Os perfis estudados no topo e meia encosta mostraram que a atuação do processo de bauxitização deu-se com conservação das texturas da rochamãe, formando assim perfis isalteríticos.

As alteritas estudadas são constituídas por gibbsita, caulinita, goethita mais quartzo e opacos, além das concreções de manganês. As bauxitas apresentam gibbsita como o principal mineral de $\mathrm{Al}$, enquanto a argila apresenta caulinita associada aos demais minerais citados.

A caracterização geoquímica mostra um comportamento diferenciado dos elementos em relação a bauxitas e argilas. Os elementos de comportamento residual mostram-se mais enriquecidos nas bauxitas, enquanto os de comportamento intermediário, quando se concentram, o fazem principalmente nas argilas. Ainda foi identificada a associação dos elementos em três grupos, relacionados ao $\mathrm{Al} \mathrm{e} \mathrm{H}_{2} \mathrm{O}^{+}$, ao $\mathrm{Fe}$ e às concreções de Mn. As associações primárias presentes nos anfiboúitos foram apenas parcialmente conservadas durante a laterização (Fe-Ti-V-TR, perdendo as TR e incorporando Be e Zr), 
enquanto outras associações são tipicamente secundárias, ou seja, formadas durante o processo de intemperismo. É o caso da neogênese da litioforita e da associação com a gibbsita (Al $\mathrm{e}_{2} \mathrm{O}^{+}$).

As condições climáticas que atuaram durante a formação destes perfis foram agressivas, com capacidade de dissolver parcialmente o quartzo em todos os níveis do perfil de alteração. Em regiões de drenagem intensa, atuou um processo de ferraiitização dos anfibolitos com ferruginização da hornblenda e à alitização dos plagioclásios e, eventualmente, clinozoisita. Uma deferruginização incipiente foi sugerida pela análise fatorial e indicada pela presença de uma geração de goethita bem cristalizada, principalmente nas partes inferiores dos perfis. Condições de drenagem menos intensa ou períodos mais secos levaram a uma dessilicificação parcial, com a transformação dos aluminossilicatos em caulinita, caracterizando um processo de monossial itização.

A falta de observação de amostras da base do perfil de alteração dificultou a definição da gênese do depósito e, principalmente, da tendência atual da alteração. Entretanto, as referências à bauxita maciça assentando diretamente sobre os anfibolitos, nos topos (Beljaviskis et al. 1984), a presença de numerosos blocos de anfibolito com córtex bauxítico e a conservação das texturas observada em todas as seções delgadas de bauxita são argumentos suficientes para considerar que a bauxita laterítica de Nazaré Paulista desenvolveu-se por bauxitização direta dos ortoanfibolitos da Seqüência Metabásica da Serra do Itaberaba.

Agradecimentos As autoras gostariam de agradecer ao Fundo de Apoio à Pesquisa (FAP-UNICAMP), ao Instituto de Pesquisas Tecnológicas do Estado de São Paulo (IPT) e ao PROMINERIO (SCT/SP) pelo suporte financeiro que possibilitou a execução dos trabalhos de campo e das análises químicas; e, especialmente, aos geólogos José Affonso Saragiotto e José Eduardo Zaine que as acompanharam nas primeiras idas ao campo.

\section{REFERÊNCIAS BIBLIOGRÁFICAS}

BELJAVISKIS, P.; JULIANI,C.; UCHOA, M.L.A.; PEROSA, P.T.Y.; TANNO, L.C: MARTINS, F.A.G. 1984. Prospecção de bauxita nas Serras do Itaberaba e Pedra Branca - SP. Ciências da Terra, 10:20-24.

BOULANGÉ, B. 1984. Lês Formations Bauxitiques Latéritiques de Cote $D$ '/voire. Paris, ORSTOM.363p.(TravauxetDocumentsderORSTOM, 175).

BULLOCK.P.; FEDOROFF, N.; JONGERIUS, A.; STOOPS, G.; TURSIN A, T. 1985.Handbookfor Soil Thin Section Description. Albr|ghton,Wayne Research Publications. $152 \mathrm{p}$.

COUTINHO, J.M.V.; RODRIGUES, E.P.; SUEMITSU, A.; JULIANI, C.; BELJAVISKIS, P.; PEROSA, P.T.Y. 1982. Geologia e petrologia da seqüência vulcano-sedimentar do Grupo São Roque na Serrado Itaberaba. In: CONGR. BRÁS. GEOL., 32. Salvador, 1982. Anais... Salvador, SBG. v. 2 , p. $624-640$.

DELVIGNE, J. 1965. Pédogenèse en Zone Tropicale: la Formation dês Minérauxen Millieu Ferralitique. Paris, ORSTOM/Dunod. 177 p.

FORMOSO, M.L.L.; RETZMANN, K.; VALETON, 1.1989. Fractionation of rare earth elements in weathering profiles on phonol ites in the areaof Lages, Santa Catarina, Brazil. Geochim. Brasiliensis, III(1):51-61.

FRASCA, M.H.B.O.; COUTINHO, J.M.V.; RODRIGUES, H.P.; FIGUEIREDO, M.C.H.; YAMAMOTO, J.K.; ZAINE, J.E.; BRAGA, T.O. 1987. Estudo petrográfico-litoquímico da seqüência vulcano-sedimentar de Itaberaba- SP. In: SIMP. REG. GEOL., 6. Rio Claro, 1987. Atas... SBG/ NSP. v.1, p. 63-82.

HASUI, Y.; CARNEIRO, C.D.R.; BISTRICHI, C. A. 1978. Osgranitóides da região de dobramentos sudeste nos Estados de São Paulo e Paraná. In: CONGR. BRÁS. GEOL., 30. Recite, 1978. Anais... Recife, SBG. v. 6, p. 2579-2593.

IPT 1981. Avaliação Preliminar das Potencialidades das Ocorrências Minerais do Estado de São Paulo. São Paulo, DMGA/Institutode Pesquisas Tecnológicas do Estado de São Paulo S/A. (Rei. Int. 15.849).

IPT 1982. Avaliação das Ocorrências de Bauxita da Região de Nazaré Paulista. São Paulo, DMGA/Instituto de Pesquisas Tecnológicas do Estado de São Paulo S/A. (Rei. Int. 17.257).
IPT/PROMINERIO1981. Mapa Geomorfológico do Estado de São Paulo. São Paulo, Secretariada Indústria, Comércio, Ciênciae Tecnologia do Estado de São Paulo. 2 v.

JULIANI, C.; BELJAVISKIS, P.;SCHORSCHER, H.D. 1986. Peírogênese do vulcanismo e aspectos metalogenéticos associados. In: CONG. BRAS. GEOL., 34. Goiânia, 1986. Anais... Goiânia, SBG. v. 2, p. 730-747.

LOPES, L.M. 1987. A EvoluçãoMineralógica, Micromorfológica e Química da Bauxita e Materiais Correlatas da Região a NE de Mirai, Minas Gerais. São Paulo, 120 p. (Dissertação de Mestrado, IG/USP).

OLIVEIRA, S.M.B.de 1985.Gênese da bauxita de Lages-SC.flo/. IG-USP 16:46-81. (SérieCientífica)

OLIVEIRA, S.M.B. \& SILVA, M.L.M.C. 1990. Comportamento das terras raras em bauxitas derivadas da laterização das rochas básicas. In: CONG. BRAS. GEOL., 36. Natal, 199Q.Anais... Natal, SBG. v. 2, p.912-919.

ROQUIN, C.; FREYSSINET, Ph.;ZEEGERS, H.;TARDY, Y. 1990. Element distribution patterns in laterites of southern Mali: consequence for geochemical prospecting and mineral exploration. Applied Geoch., 5(3):303-315

SILVA, M.L.M.C. \& OLIVEIRA, S.M.B. 1989. Ferruginous bauxite from Nazaré Paulista (São Paulo, Brazil): Geochemical evolution. Travaux ICSOBA, 19:141-15\&.

TOLEDO-GROKE,M.C. \&MELFI,A.J. 1982. Aspectos micromorfológicos da evolução bauxítica de rochas básicas e alcalinas no Estado de São Paulo.Estudo dos depósitos de CurucutueLavrinhas. In: CONG. BRAS. GEOL., 32. Salvador, 1982. Anais... Salvador, SBG. v. 2, p. 702-713.

MANUSCRITO A696

Recebido em 12 de marco de 1991 RevisSo do autor em 19 de dezembro de 1991 Revisão aceita em 23 de dezembro de 1991 